\title{
Cholepyrrhin-Concretion aus der Galle eines Mannes.
}

Die vorstehende Alhandlung des Hrn. Prof. Schmid veranlasst mich zur Mittheilung einer Untersuchung einer Gallenconcretion, welche mir schon im Jahre 1830 von einem hiesigen Arzte zur Vervollständigung meiner SammJung thierischer Concretionen uibergeben worden war. Die Concretion war bei der Section der Leiche eines Mannes in der Gallenblase gefunden worden. Ihr Aeusseres zeigte schon bestimmt ihre gänzliche Verschiedenheit von den gewöhnlichen aus Cholesterin bestehenden Gallensteinen. Die ausführlichere Prülung derselben ist unter meiner Leitung von IIrn. Thieme vorgenommen worden.

Die Concretion bestand in mehreren linsen-bis erbsengrossen Körnern von traubiger Gestalt und dunkelbrauner, fast schwarzer Farbe, ohne Geruch und ohne bemerkenswerthen Geschmack. Auf der Oberfläche zeigten sie sich höckerig, auf dem Bruch körnig und zum Theil krummschalig und hohl. Sie waren leicht zerreiblich und gaben ein dunkelochergelbes Pulver.

Bei der Erhitzung in der Glasröhre entwickelten sie weisse, später gelbe, widerig riechende Dämpfe und ein braunes empyreumatisches Oel und zugleich ziemlich viel Ammoniak. Es hinterblieb eine poröse, alkalisch reagirende Kohle, worin sich Schwefelcalcium, kohlensaurer Kalk und Eisen erkennen liessen.

Mit Weingeist von 84 Proc. digerirt, lieferten sic eine dunkelgrïne, neutral rcagirende Lösung, welche mit essigsaurem Bleioxyd einen schmutzig - weissen, in Essigsäure auflöslichen Niederschlag gab; mit salpetersaurem Quecksilberoxydul einen grauweissen, in verdiunnter Salpetersäure auflöslichen Niederschlag; mil salpetersaurem Silberoxyd einen flockigen, in Ammoniak auflöslichen N.; mit Eisenchlorid einen flockigen, in Essigsäure auflöslichen Niederschlag; mit schwefelsaurem Kupferoxyd einen flockigen, schmutzig-grünen N. Hingegen bewirkten ätzende und kohlensaure Alkalien, Gerbsäure, Quecksilberchlorid, Zinnchlorür 
und chromsaures Kali keine Trübung. Salpetersäure verwandelte die grüne Farbe in eine hyacinthrothe. - Beim Verdampfen der Lösung schieden sich grüne Flocken ab. Als der grüne Rückstand im Platin erhitzt wurde, entwickelte sich anfangs ein dem Caramel ähnlicher, später ein unangenehmer Geruch nach versengenden Federn. Die sehr geringe Kohle enthielt eine Spur schwefelsauren Kalk.

Die mit Weingeist ausgekochte Concretion wurde nun mehrmals mit Wasser ausgezogen. Es wurde aber nur ein wenig schwefelsaurer Kalk aufgelöst.

Hierauf wurde die Concretion mit Aether behandelt, allein dadurch nur eine Spur eines grünlichen Feltes ausgezogen.

Verdünnte Salpetersäure veränderte nun die Concretion während gelinder Digestion und färbte sie nach einander grün, blassroth bis gelb, wobei eine starke Gasentwickelung statt fand. Ein kleiner Theil blieb unaufgeJöst. - Die filtrirte, röthlichgelbe, schwach saure Fliissigkeit reagirte nur auf Kalk, sehr schwach auf Talkerde und ein wenig auf Eisenoxyd.

Zuletzt wurde noch Kali angewendet, worin sich der Rest der Concretion vollkommen auflöste. Die Auflösung war braungrün, enthielt keinen merklichen Ueberschuss von Kali. Sie gab mit wenig Salpetersäure dunkelgrüne Flocken, welche durch concentritte Salpetersäure roth und dann gelb wurden. Zinnchlorïr fällte bräunlich-griine Flocken; essigsaures Kupferoxyd gab einen starken grünlichgrauen, Eisenvitriol einen dunkelgrünlichgrauen, Eisenchlorid einen braunen Niederschlag; andere Metallsolutionen gaben ähnliche Niederscliläge.

Aus diesen Versuchen folgt also, dass diese Concretionen in nichts anderem, als in dem Farbstoff der Galle nebst kleinen Mengen von Fett, von kohlensaurem und schwefelsaurem Kalk, von kohlensaurer Talkerde und von Eisenoxyd bestanden. Das sogenannte Biliverdin und Bilifulvin, beide als Metamorphosen des Cholepyrrhin von 
Berzelius*) scheiden sich im isolirten Zustande. wie man weiss, nur sehr selten aus der Menschengalle $a b^{* *}$ ), während dieses die gewöhnliche Art der Concretionen in der Galle des Ochsen ist. Meine Sammlung thierischer Concretionen enthält ein Paar solcher Gallensteine, welche eine ziemliche Grösse besassen, aber allmälig zerfallen sind und im Innern eine intensiv rothgelbe Farbe zeigen.

H. W a ck en roder.

\section{Amylumgehalt der Wachholderbeeren; von \\ Dr. Witting.}

Die Gegenwart des Amylum in den grünen unreifen Wachholderbeeren, nachgewiesen durch die Herren Dr. A sch off in Bielefeld und Herford, habe ich ebenfalls bestätigt gefunden. Es ist hierbei nothwendig, dieselben zu zerquetschen, mit destillirtem Wasser breiartig anzurühren, und demnächst das Flüssige durch neue (natürlich nicht mit Amylum behandelte Leinwand) zu sondern, indem wiederholt neue Antheile Wasser hinzugefügt werden. Das Sediment wird zunächst mit einigen Granen Jodkalium versetzt, erhitzt, und nun einige Tropfen concentrirte Säure, sodann einige Tropfen Chlorwasser hinzugefiugt. Es erfolgt nun das bläuliche Colorit.

*) S. Berzeliu s' Jahresbericht. Jahrg. 22. Hft. 3. p. 562. Bekanntlich identificirt Berzelius jetzt das Biliverdin mit Chlorophyll.

* *) Vergl. u. A. Berzelius' Lehrbuch der Chemie. Bd. 9. p. 311. 